\title{
A national study of Continuous Professional Competence (CPC) amongst pre-hospital practitioners
}

\author{
Shane Knox ${ }^{1,2}$, Walter Cullen ${ }^{1}$ and Colum P. Dunne ${ }^{1^{*}}$
}

\begin{abstract}
Background: Internationally, continuing professional competence (CPC) is an increasingly important issue for all health professionals. With the introduction of the first CPC framework for Emergency Medical Technicians (EMTs) and the imminent introduction of CPC for Paramedics and Advanced Paramedics (APs) in Ireland, this study aimed to identify attitudes towards CPC and factors that might influence such a framework.
\end{abstract}

Methods: All EMTs ( $n=925)$, Paramedics and APs $(n=1816)$ registered in Ireland were invited by email to complete an anonymous on-line survey. The study instrument was designed based on continuous professional development (CPD) questionnaires used by other healthcare professions. Quantitative and qualitative analyses were performed.

Results: The overall response rates were: EMTs $43 \%(n=399)$, Paramedics and APs $43 \%(n=789)$, with $82 \%$ of APs and $38 \%$ of Paramedics participating. The majority of participants in all groups agreed that registration was of personal importance and that evidence of CPC should be maintained; $39 \%$ of Paramedics/APs and $78 \%$ of EMTs believed that persistent failure to meet CPC requirements should mandate denial of registration. From a pre-determined list of activities, in excess of $88 \%$ of all respondents indicated practical training scenarios, cardiac re-certification, e-learning supplemented by related practice, and training with simulation manikins were most relevant to these roles. However, least relevant to them were: e-learning alone (Paramedic/AP $36 \%$; EMT 35 \%); project work (Paramedic/AP 27 \%; EMT 48 \%); and appraisal of journal articles (Paramedic/AP 24 \%; EMT 39 \%).

Conclusion: Irish EMTs, Paramedics and Advanced Paramedics were supportive of CPC and favoured a 'mixed' model approach which includes: blended learning, practical skills, simulation, practical/team-based exercises, e-learning combined with practical skills, and evidence of patient contact. It is hoped that these insights will inform the CPC guidelines to be introduced.

Keywords: EMTs, Paramedics, Advanced Paramedics, Continuous Professional Development, Continuous Professional Competence

\section{Background}

Ambulance services provided by pre-hospital practitioners in Ireland are governed by the Regulator, the Pre-Hospital Emergency Care Council (PHECC), an independent statutory agency responsible for implementing standards of education and training for pre-hospital emergency care practitioners.

\footnotetext{
* Correspondence: colum.dunne@ul.ie

${ }^{1}$ Graduate Entry Medical School and Centre for Interventions in Infection, Inflammation \& Immunity (4i), University of Limerick, Castletroy, Limerick, Ireland

Full list of author information is available at the end of the article
}

The Regulator maintains a register of pre-hospital practitioners and those licensed are permitted legally to practice using guidelines developed by the Regulator to manage patients. There are three level of practitioner: Emergency Medical Technician (EMT), Paramedic and Advanced Paramedic (AP).

At a professional level, pre-hospital care in Ireland is provided by the Health Service Executive's (HSE) National Ambulance Service (NAS) and (in parts of Dublin city) the 'Dublin Fire Brigade'. Staff who respond to pre-hospital incidents are all trained to Paramedic or Advanced Paramedic (AP) level. In addition, pre-hospital 
care is provided at sporting and other public events by Emergency Medical Technicians, mostly affiliated to voluntary organisations: e.g., Civil Defence, Order of Malta Ireland, St. John Ambulance and the Irish Red Cross.

In Ireland, currently, once qualified there is no regulatory requirement for the practitioner, at paramedic or advanced paramedic level, to provide evidence of competence, or any link between competence and registration to practice. However, it is reasonable that practitioners and consumers alike view maintenance of competency as a basic element of ethical and responsible practice [1]. Therefore, the Regulator's strategic plan (2011-2014) stated the need to develop and implement a continuous professional competence (CPC) framework [2].

One of the functions of a healthcare Regulator is to protect the public by ensuring that acceptable standards of care are being provided [3]. Previous studies have assessed EMT, Paramedic and Advanced Paramedic (AP) training and continuing education in Ireland [4-6] and internationally [7-9]. However, in this study we wished to determine, for the first time, the attitudes of Irish EMTs, Paramedics and APs towards CPC, their preferred activities, delivery formats and perceived relevance to their roles.

It is accepted that any form of compulsory education is incongruent with the nature of both being a professional and adult; professionals should be self-directed sufficiently to participate autonomously in educational activities rather than being compelled to do so [10]. That, combined with a proliferation of training and education formats that, without justification through specific needs assessment, are unlikely to be effective [11] encouraged us to devise a short answer survey to guide and inform the impending $\mathrm{CPC}$ implementation in Ireland.

Additionally, such an approach appears to be relatively rare in the published literature and may, therefore, inform or prove useful to others engaged in developing pre-hospital or other professional CPC/CPD or competency standards in other Countries.

\section{Methods}

\section{Participants}

In February 2012, all registered Paramedics and APs in Ireland with valid email addresses $(n=1816)$ were contacted and provided a link to a Survey Monkey ${ }^{\text {max }}$ online study instrument and to a concise, unbiased explanation of the survey topic. Similarly, in July/ August 2012, all registered EMTs $(n=925)$ were contacted by email and provided a similar link to the on-line survey. A written request to the Registrar, the person responsible for maintaining the Register of pre-hospital practitioners, was made outlining the purpose of the research and seeking permission to contact these registrants. Written permission was granted on the basis that the Registrar would circulate the survey details on behalf of the authors. A letter of introduction was sent to registrants to explain the purpose of the research and described how consent would be implied should registrants participate in the research. Participation was voluntary and anonymous. The design and conducting of the study, taking into consideration published healthcare professions' questionnaires relating to continuous professional development (CPD) [12-14] were approved by the Ethics Committee of the Faculty of Education and Health Sciences, University of Limerick, Ireland and the Research Ethics Committee of the Health Services Executive Mid-Western Regional Hospital, Limerick, Ireland.

\section{Data collection and analysis}

Health professionals are increasingly expected to identify their own learning needs through self-assessment $[15,16]$. Therefore, the survey questions were designed to elicit participants' views on CPC. The survey was piloted after a presentation regarding $\mathrm{CPC}$ to 120 EMTs at a biannual conference in 2011 [17]. Responses were recorded and summarized at the event using mind mapping software (mindGenius ${ }^{\circ}$ ). Following analysis of the exercise, the design of the questionnaire was finalised and trialed using 12 EMTs and, subsequently, by a further 20 registered Paramedics/APs. All trial participants were excluded from the study analyses.

The questionnaire (Additional File 1) comprised questions relating to: demographics; opinions regarding CPC; CPC portfolio development; linkage of CPC and registration. The response data were downloaded from Survey Monkey ${ }^{\mathrm{Tm}}$ software to an electronic data file and quantitative analysis was performed using SPSS version 20.0. To make analysis more meaningful, responses to the five-point Likert scale were analysed using three options, 'strongly agree/agree', 'undecided' and 'strongly disagree/disagree'. Not every question was answered by every respondent and, therefore, answers are described by number and percentage of responses to specific questions.

\section{Results}

\section{Demographics}

There were 789/1816 responses received from Paramedics and Advanced Paramedics (APs), $43 \%$ of all registered Paramedics and APs with email addresses, of whom 598 were Paramedics (38\% of the national cohort) and 191 were Advanced Paramedics (82\% of the national cohort). From the EMT cohort, there were 399/925 responses received (43\% of all registered EMTs) (Fig. 1). The majority of respondents 




Fig. 1 Registered Emergency Medical Technicians (EMTs), Paramedics and Advanced Paramedics (APs) in Ireland and number of responses

were male: Paramedic/AP $85 \%$, 670: EMT $70 \%$, 271; with female responses of $15 \%$ Paramedic/AP and $30 \%$ EMT (Table 1). EMT responses were reasonably well dispersed across the Irish voluntary organisations: Order of Malta (96, 24 \%), Civil Defence (80, $20 \%$ ), St. John Ambulance (29, 7 \%) and the Irish Red Cross (97, $24 \%)$. There was considerably less participation by EMTs employed by the Irish State (10 \%) such as the Defence Forces, Irish Health Service, An Garda Síochána (police), Fire Service, Coastguard, etc. and private ambulance services (10 \%) with those described as 'not affiliated' to an organisation (5\%). Paramedic and AP respondents predominantly served in the Irish National Ambulance Service (71 \%) and the Dublin Fire Brigade (14 \%) (Fig. 2).

\section{Attitudes towards Continuous Professional Competence} and registration

Registration with the Regulator was considered personally important by $89 \%$ (697) of Paramedics/APs and $97 \%$ (381) of EMTs. In addition, 77 \% (615) of the Paramedics/ APs and $86 \%$ (343) of EMTs stated that CPC was extremely important professionally. Most Paramedic/AP respondents $(74 \%, 584)$ agreed that $\mathrm{CPC}$ should be a condition of registration to practice, while $95 \%$ (341) of EMTs held that view. $67 \%$ (526) of the Paramedic/AP respondents agreed that Paramedics and APs should maintain evidence of CPC activities to ensure registration, while $82 \%$ (329) of EMTs believed that to be the case.

$39 \%$ (307) of Paramedics/APs agreed with the suggestion that those who fail to meet $\mathrm{CPC}$ requirements 
Table 1 Gender and registration level

\begin{tabular}{|c|c|c|c|}
\hline Registration Status with Regulatory Body (PHECC) & Male & Female & Total \\
\hline Advanced Paramedic & $138(88 \%)$ & $19(12 \%)$ & 157 \\
\hline Advanced Paramedic Intern & $19(90 \%)$ & $2(10 \%)$ & 21 \\
\hline Advanced Paramedic Trainee & $11(85 \%)$ & $2(15 \%)$ & 13 \\
\hline Paramedic & $451(85 \%)$ & $81(15 \%)$ & 532 \\
\hline Paramedic Intern & $38(78 \%)$ & $11(22 \%)$ & 49 \\
\hline Paramedic Trainee & $14(82 \%)$ & $3(18 \%)$ & 17 \\
\hline Emergency Medical Technician (EMT) & $271(70 \%)$ & $115(30 \%)$ & 386 \\
\hline Response Totals & $941(80 \%)$ & $234(20 \%)$ & 1175 \\
\hline Gender not reported & & & 13 \\
\hline Response Percentage: EMT & $70 \%$ & $30 \%$ & \\
\hline Response Percentage: paramedic/advanced paramedic & $85 \%$ & $15 \%$ & \\
\hline
\end{tabular}

should be allowed to register only at the level below their current registration, but $23 \%$ (179) did not support that proposition.

\section{CPC activities}

A small majority of Paramedics/APs surveyed (53\%), although not obligated, maintained a professional portfolio at the time of the survey. xThis majority was greater (69 \%) in the EMT group. Fifty seven per cent of Paramedics/APs and $51 \%$ of EMTs had completed greater than 20 hours of CPC activities in the prior 12 months, with $20 \%$ of Paramedics/APs and $28 \%$ of EMTs having completed more than 60 hours (Fig. 3). When the Paramedics/APs were queried as to what they believed should be the appropriate levels of $\mathrm{CPC}$ required in a 12-month period, $35 \%$ believed $21-40$ hours , $26 \%$ believed 41-60 hours, and $17 \%$ believed 20 hours would be adequate (Fig. 4). Yet, $34 \%$ of EMTs believed that 21-40 hours were adequate, $23 \%$ that $41-60$ hours, and $20 \%$ (58) that 20 hours would be adequate.

\section{Consultation regarding specific models of Continuous Professional Competence}

Overall, the majority of EMT (88 \%) and Paramedics/AP (77 \%) respondents favoured the introduction of CPC by the Regulator using a 'mixed' model approach of combining 'mandatory' and 'voluntary' activities, with $84 \%$ of EMTs and $77 \%$ of Paramedics/APs supportive of minimum standard requirements that include evidence

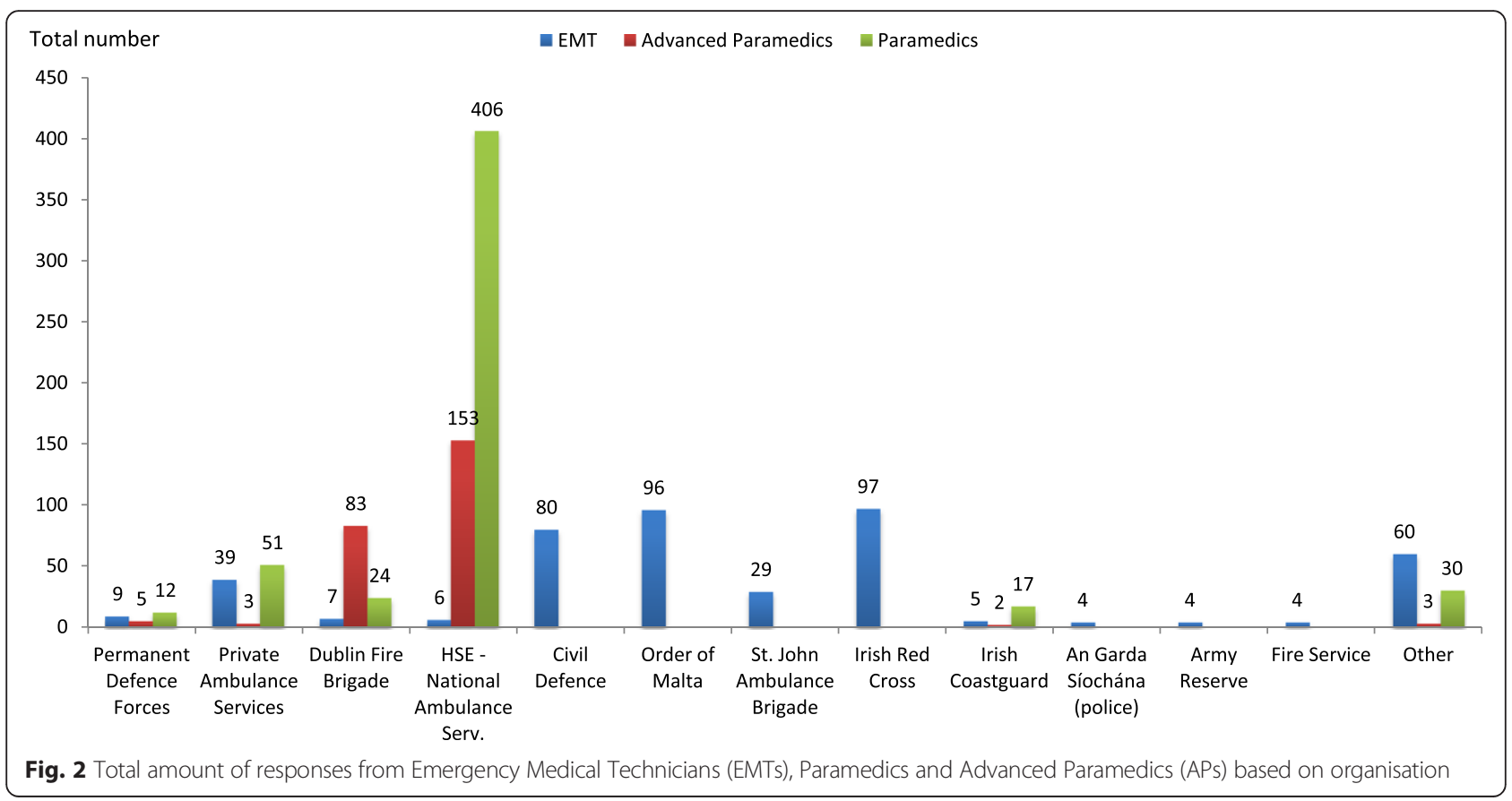






Fig. 3 Number of CPC hours recorded in the prior 12-month period by Emergency Medical Technicians (EMTs), Paramedics and Advanced Paramedics (APs)

of patient care report (PCR) completion, clinical practice guidelines (CPGs) compliance and patient management.

Most respondents considered practical type learning relevant to their roles (Figure 5 and Table 2): practical training scenarios, EMT 83 \% (266), Paramedic/Advanced Paramedic $94 \%$ (582); annual cardiac first response revalidation: EMT 97 \% (311), Paramedics/APs 85 \% (517); access to e-learning followed by related practice EMT $91 \%$ (291), Paramedics/APs $92 \%$ (566); and training on simulation manikins EMT 93 \% (297), Paramedics/APs 88 \% (535).
Ninety five per cent of EMTs (306) surveyed would value the opportunity to complete duties with Paramedics and Advanced Paramedics.

The activities that received the highest 'not relevant' responses were: 'e-learning modules only and no related practice EMT $32 \%$ (101), Paramedics/APs $36 \%$ (210); project work EMT16\% (50), Paramedics/APs $27 \%$ (166); appraisal of journal publications EMT $20 \%$ (62), Paramedics/APs $24 \%$ (147); and, for EMTs only, First Aid competitions $25 \%$ (78).

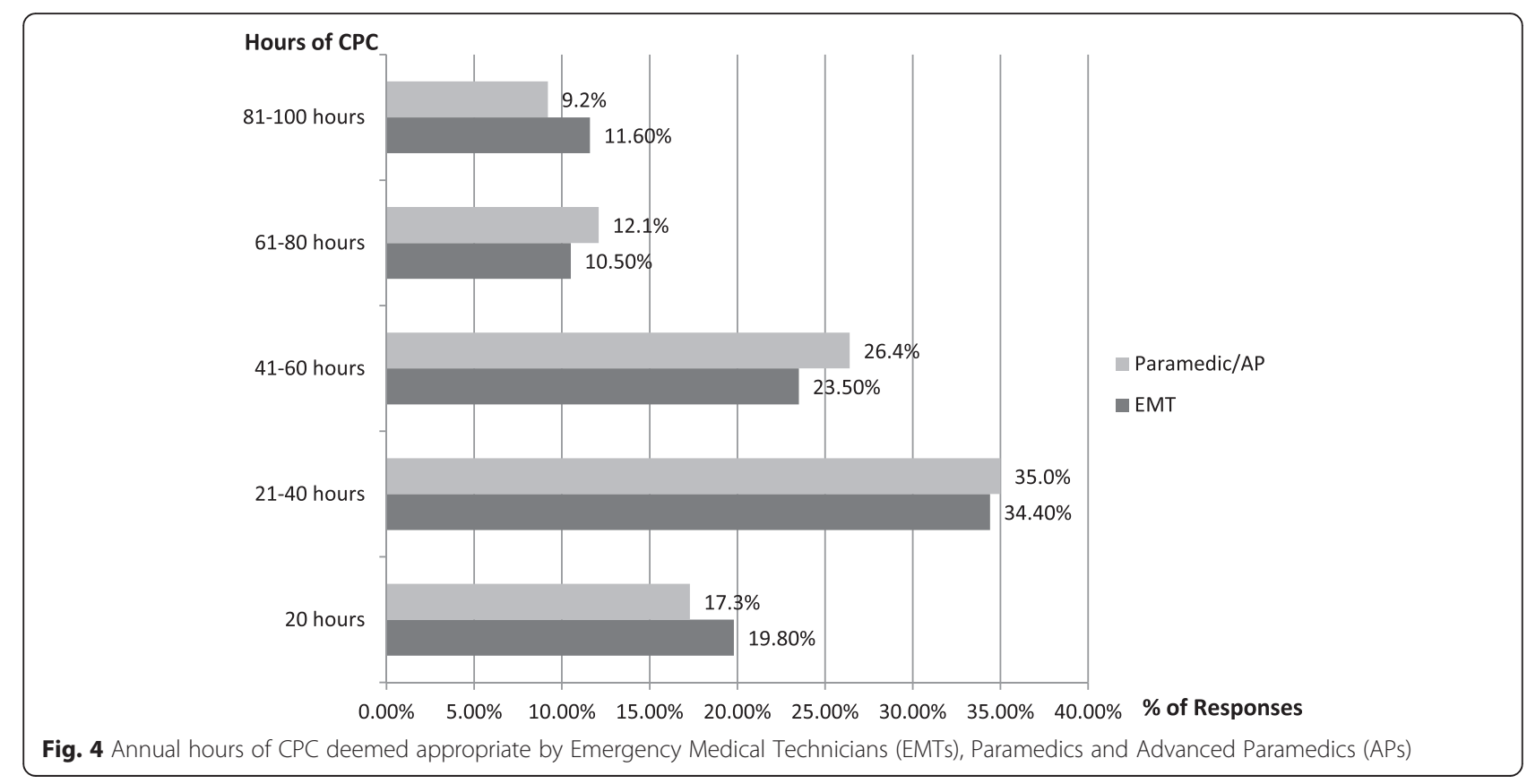


Table 2 Relevance of potential CPC activities

\begin{tabular}{|c|c|c|c|c|c|c|c|c|c|c|}
\hline \multirow{2}{*}{$\begin{array}{l}\text { Relevant }=\text { Very relevant/Relevant } \\
\text { Not relevant = Not relevant/Nery irrelevant } \\
\text { P/AP = Paramedic/Advanced paramedic } \\
\text { N/A = Not asked/Not applicable } \\
\% \text { of total = \% of total responses }\end{array}$} & \multicolumn{4}{|c|}{ Relevant responses } & \multicolumn{4}{|c|}{ Not relevant responses } & \multicolumn{2}{|c|}{$\begin{array}{l}\text { Total responses for } \\
\text { question }\end{array}$} \\
\hline & P/AP & $\%$ of total & EMT & $\%$ of total & P/AP & $\%$ of total & EMT & $\%$ of total & P/AP & EMT \\
\hline Practical training scenarios & 582 & $94 \%$ & 266 & $83 \%$ & 9 & $1 \%$ & 2 & $1 \%$ & 613 & 321 \\
\hline Going on duty with Paramedics or APs & N/A & N/A & 306 & $95 \%$ & N/A & N/A & 7 & $2 \%$ & N/A & 321 \\
\hline Annual Cardiac re-certification & 566 & $92 \%$ & N/A & N/A & 29 & $4 \%$ & N/A & N/A & 616 & N/A \\
\hline Access to e-learning followed by related practice & 555 & $90 \%$ & 291 & $91 \%$ & 11 & $2 \%$ & 5 & $2 \%$ & 617 & 320 \\
\hline Access to medical journals/medical books & 538 & $88 \%$ & 266 & $83 \%$ & 17 & $3 \%$ & 11 & $3 \%$ & 615 & 320 \\
\hline Training on a simulation manikin & 535 & $88 \%$ & 297 & $93 \%$ & 25 & $4 \%$ & 7 & $2 \%$ & 613 & 321 \\
\hline Attending courses accredited by Regulator & 518 & $84 \%$ & 307 & $96 \%$ & 30 & $5 \%$ & 2 & $1 \%$ & 614 & 319 \\
\hline Annual Cardiac First Response revalidation & 517 & $85 \%$ & 311 & $97 \%$ & 60 & $10 \%$ & 6 & $1 \%$ & 611 & 322 \\
\hline Evidence of current CPG compliance & 489 & $80 \%$ & N/A & N/A & 25 & $4 \%$ & N/A & N/A & 611 & N/A \\
\hline Mentoring others & 483 & $79 \%$ & 277 & $87 \%$ & 47 & $8 \%$ & 12 & $4 \%$ & 613 & 317 \\
\hline Major incident/Emergency exercises & 480 & $78 \%$ & 297 & $93 \%$ & 34 & $5 \%$ & 7 & $2 \%$ & 612 & 319 \\
\hline Regular practical assessments & 458 & $75 \%$ & 253 & $79 \%$ & 48 & $8 \%$ & 13 & $4 \%$ & 613 & 319 \\
\hline Working in a related hospital department & 453 & $74 \%$ & N/A & N/A & 64 & $10 \%$ & N/A & N/A & 612 & N/A \\
\hline Keeping a portfolio of CPC activities & 441 & $73 \%$ & 288 & $90 \%$ & 55 & $9 \%$ & 4 & $1 \%$ & 606 & 319 \\
\hline Relevant conferences & 405 & $66 \%$ & 246 & $78 \%$ & 74 & $12 \%$ & 18 & $6 \%$ & 613 & 317 \\
\hline Lecturing/teaching & 403 & $65 \%$ & 276 & $86 \%$ & 76 & $12 \%$ & 15 & $5 \%$ & 612 & 319 \\
\hline Appraisal with senior Training Officer (or above) & 373 & $61 \%$ & 248 & $78 \%$ & 92 & $15 \%$ & 20 & $6 \%$ & 612 & 319 \\
\hline Being a Tutor & 349 & $57 \%$ & 251 & $79 \%$ & 95 & $16 \%$ & 19 & $6 \%$ & 607 & 316 \\
\hline Appraisal with a doctor/medical supervisor & 309 & $51 \%$ & 207 & $66 \%$ & 115 & $19 \%$ & 37 & $11 \%$ & 610 & 320 \\
\hline Being an examiner & 309 & $51 \%$ & 222 & $69 \%$ & 116 & $19 \%$ & 30 & $9 \%$ & 607 & 319 \\
\hline Case study review & 283 & $46 \%$ & 204 & $64 \%$ & 114 & $19 \%$ & 20 & $6 \%$ & 610 & 317 \\
\hline Project work & 223 & $37 \%$ & 152 & $48 \%$ & 166 & $27 \%$ & 50 & $16 \%$ & 607 & 318 \\
\hline E-learning modules only and no related practice & 203 & $33 \%$ & 109 & $35 \%$ & 210 & $36 \%$ & 101 & $32 \%$ & 607 & 313 \\
\hline First Aid competitions & N/A & N/A & 159 & $50 \%$ & N/A & N/A & 78 & $25 \%$ & N/A & 315 \\
\hline Appraisal of journal publications & 188 & $31 \%$ & 124 & $39 \%$ & 147 & $24 \%$ & 62 & $20 \%$ & 607 & 316 \\
\hline
\end{tabular}

In addition to the practical-type, hands-on activities preferred for CPC maintenance, EMTs, Paramedics and APs also considered the following activities very relevant or relevant in maintaining CPC: access to medical journals/books EMT 83 \% (266), Paramedics/APs 88 \% (538/ 615); attending courses accredited by the Regulator EMT 96 \% (307), Paramedics/APs 84 \% (518/614); evidence of current CPG compliance (EMTs were not asked this question) Paramedics/APs $80 \%$ (489); mentoring others EMT $87 \%$ (277), Paramedics/APs $79 \%$ (483); major incident/emergency exercises EMT $93 \%$ (297), Paramedics/APs $78 \%$ (480/612); regular practical assessments EMT 79 \% (253), Paramedics/APs $75 \%$ (458); working in a related hospital department (EMTs were not asked this question) Paramedics/APs $74 \%$ (453); keeping a portfolio of CPC activities EMT $90 \%$ (288), Paramedics/APs $73 \%$ (441); attending relevant conferences EMT 78 \% (246), Paramedics/APs $66 \%$
(405); lecturing/teaching EMT 86 \% (276), Paramedics/ APs $65 \%$ (403); appraisal with a senior Training Officer EMT 78 \% (248), Paramedics/APs 61 \% (373); being a tutor EMT 79 \% (251), Paramedics/APs 57 \% (349); appraisal with a doctor/medical supervisor EMT $66 \%$ (207), Paramedics/APs 51 \% (309); being an examiner EMT 69 \% (222), Paramedics/APs 51 \% (309); case study review EMT 64 \% (204),Paramedics/APs 46 \% (283).

\section{Discussion}

Some literature reports the development of ambulance CPD programmes internationally [7, 9]. Although CPD is more likely to lead to a change in practice when a needs assessment has been conducted [18], literature reporting consultation with practitioners prior to the introduction of such programmes is limited.

This first study of attitudes towards professional competence among EMTs, Paramedics and APs in Ireland 


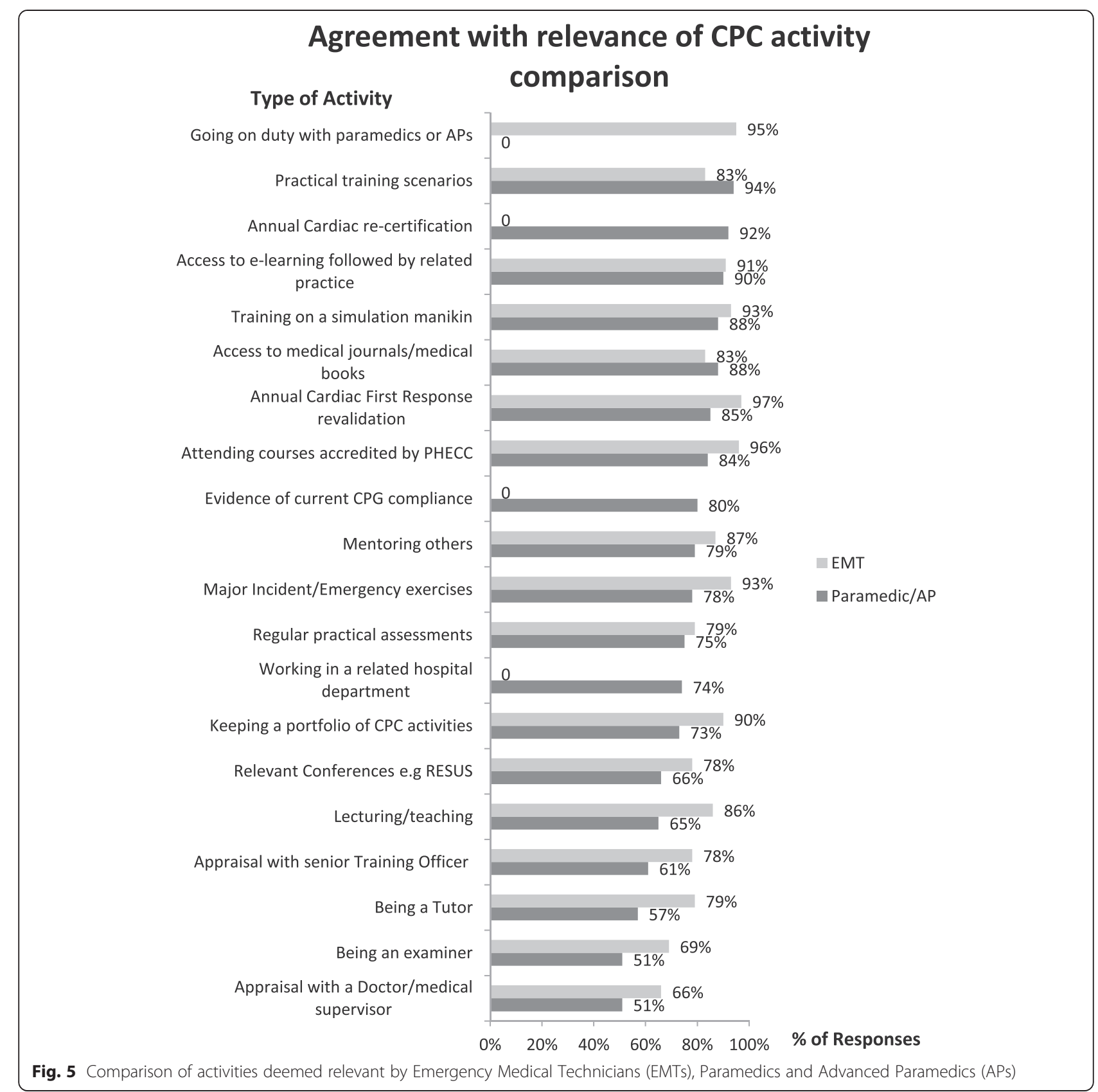

suggests a genuine enthusiasm for the introduction of $\mathrm{CPC}$, with all groups indicating that CPC was of personal importance to them. Also there is evidence from their responses that all groups believed in the need for $\mathrm{CPC}$ and the link with registration and that the majority of these practitioners were already maintaining CPC portfolios (Fig. 3).

\section{Demographics}

The majority of total responses across all levels were from males 941 (80 \%) with females at 234 (20 \%) (Table 1) and from registrants within the National
Ambulance Service (NAS). This is unsurprising as the ambulance services in Ireland are provided, predominately, by the National Ambulance Service (NAS). In addition to the NAS, Dublin Fire Brigade provides ambulance services through twelve ambulance vehicles based throughout Dublin City. Both services are male dominated and employ Paramedics and Advanced Paramedics with few EMTs in either service. The NAS has, since 2012, commenced recruiting EMTs into the ambulance service but these are few in number currently standing at approximately one hundred (i.e., circa $7 \%$ of the workforce). Therefore, most registered EMTs are members of the 
Voluntary Organisations. While it could be argued these EMTs are not full-time professionals, they are committed volunteers on a national regulatory and professional register and do perform duties at large events.

\section{CPC activities}

This study identified a number of useful topics and activities that could be considered for the purpose of $\mathrm{CPC}$, and has identified some areas of low $\mathrm{CPC}$ priority for registrants.

Specifically, practical hands-on training using simulation manikins, team-based activities or e-learning followed by practical skills were preferred over nonpractical/theory-type activities. Also, there were less negative responses regarding activities related to practical skills than to theoretical skills. A study with Irish APs reinforced the concept of practical-type learning as a preferred methodology and as an effective way of maintaining competence [6] and indeed scenario-based simulations have been used since 2007 as part of routine continuing education programmes by some American emergency medical services [9]. Interactive methods, for the purposes of CPD, such as team-based learning and case-based learning, as compared to lectures, impart sustainable knowledge and lead to high satisfaction among participants [19]. For example, Davis et al. [20] in their systematic review found that interactive and mixed educational sessions were associated with a significant effect on physicians' performance, effected change in professional practice and, on occasion, healthcare outcomes.

The least relevant activities, identified by both the EMT and Paramedic/AP groups were associated with non-skills/practical, individually-based, passive activities: e-learning modules only and no related practice.

Other activities regarded as less relevant were: project work and appraisal of journal publications. This is quite different to results seen from other professions who have tended to prefer attending conferences, lectures and reading of relevant journals $[14,21]$ even though there is little evidence to suggest that attending conferences had any direct impact on improving professional practice [22].

Studies on cardiac nurses and dietitians [14, 23] have shown that journal reading was a popular preference. However, for doctors the effectiveness of continuous medical education (CME) increases as the intervention strategy becomes more active, while activities classed as passive are associated less with changes in physician performance or patient outcome [22].

\section{Model of CPC}

Groups were split in relation to opinion on annual hours of CPC that should be required; both cohorts responded similarly, and with the highest response rate to this section, stating that $21-40$ hours were adequate (see Fig. 4). The majority of both cohorts surveyed favoured a 'mixed' model approach for CPC with a similar number supporting the idea of minimum standard requirements which involved evidence of patient care. This 'mixed' model approach would allow for a 'compulsory' element to the CPC requirements and an additional 'voluntary' allowance that is still required but would allow the registrant some flexibility in deciding which activities to choose.

The benefit of mandatory CPD in healthcare professions has been debated. O'Connor's [24] study on motivating factors for nurses participating in continuing education (CPD) suggested that the mandatory nature of the education had little influence in motivating participation, while Lee et al. [25] found that $66 \%$ of Australian radiographers thought CPD should be voluntary. Friedman and Woodhead [26] suggested that those professional bodies utilising compulsory or mixed policies with respect to CPD were likely to be promoting CPD as a means of maintaining competence.

Regarding sanctions, the majority of EMTs and Paramedics/APs agreed that the practitioner should not be allowed to re-register at their current level if they failed to meet the CPC requirements. This finding is higher than from some other healthcare professions, for example $42 \%$ of pharmacists surveyed [27] favoured sanctions yet few dietitians favoured disciplinary action for those who failed to meet the registration requirements [23].

\section{Limitations}

While this first study of attitudes towards CPC among EMTs, Paramedics and APs in Ireland involved a national sample, we acknowledge some methodological considerations may limit generalisability. We report data from 1188 responses which is a relatively large number that compares well with other reported surveys [28-31], representing $43 \%$ of all registered EMTs and $43 \%$ of all registered Paramedics and Advanced Paramedics. In addition, it is important to note that the response rate from the Advanced Paramedic cohort represented $82 \%$ of those registered. Our study was limited to those with valid email addresses and clearly those for whom the subject area was of interest responded. Further research following the introduction of CPC for all three levels of Irish registered pre-hospital practitioners, may expand upon these findings.

\section{Conclusions}

There is a paucity of research conducted with registered pre-hospital practitioners in Ireland. This survey is the first to ascertain the opinions of EMTs, Paramedics and APs regarding CPC. While there is evidence of the need for pre-hospital practitioners maintaining competence in 
other ambulance services internationally e.g., Australia, UK and Canada, their guidelines are less prescriptive. In the UK, for example, the Health and Care Professions Council that regulates Paramedics, state in its guidance document that 'there is no automatic link between [evidence of] CPD and your competence' as this is not directly linked to the legislation which established that body (the Health and Social Work Professions Order 2001). Also, although all their registrants must maintain 'a continuous up-to-date and accurate record of their CPD activities', this requirement is linked to a set of professional competencies associated with the profession and are less specific. This too is the case in Australia [32] and Canada where they use their standards of competence to encourage CPD in a non-specific and generic manner across practitioner levels: 'Participate in continuing education and professional development; develop personal plans for continuing professional development; describe common quality assurance and enhancement processes' [33].

This study further suggests that there is willingness on behalf of Irish EMTs, Paramedics and APs to engage with $\mathrm{CPC}$, which is viewed as extremely important. Respondents considered it appropriate to link CPC with registration to practice and that there should be sanctions against those who do not meet $\mathrm{CPC}$ requirements.

The results of this survey demonstrate, at the very least, that emphasis will need to be placed on availability/provision of a compulsory 'mixed' model approach of CPC. This mixed model approach should include evidence of patient contact. Indeed, this varied model of $\mathrm{CPC}$ is also encouraged by the UK Health and Care Professions Regulator, requiring registrants to 'demonstrate that their activities are a mixture of learning activities relevant to current or future practice' and, although there is no explicit link to patient contacts guidelines suggest the use of critical reviews and case studies that could imply patient contacts [34].

The mixed model of CPC includes activities that are practically orientated: practical training scenarios; annual cardiac recertification; e-learning followed by related practice; training on simulation manikins. Conversely, there is less interest in non-skills/practical, individual passive learning activities: e-learning alone and no related practice; project work, journal reviews. Somewhere between twenty to sixty hours of CPC activities per annum would appear to be acceptable to Irish practitioners.

\section{Additional file}

Additional file 1: Core Questionnaire Summary. (DOCX 25 kb)

\section{Competing interests}

The authors declare that they have no competing interests.

\section{Authors' contributions}

SK conceived of the study and was involved in the design, collection of data, data analysis, and drafting of the manuscript. WC and CD (principal investigator) were involved in the conception of the study, data analysis and interpretation, and drafting of the manuscript. All authors read, reviewed the manuscript critically for intellectual content, and approved the final manuscript.

\section{Authors' information}

SK: Assistant Chief Ambulance Officer, National Ambulance Service College, Dublin, Ireland.

WC: Chair of General Practice, Graduate Entry Medical School, University of Limerick, Ireland.

CD: Chair \& Director of Research, Graduate Entry Medical School, University of Limerick, Ireland.

\section{Acknowledgements}

The authors thank the registered Emergency Medical Technicians, Paramedics and Advanced Paramedics who responded to the questionnaire. Thanks also to Dr Helen Purtill of the Statistical Consulting Unit, University of Limerick for her comments on the design and results of the survey.

\section{Funding}

Pre-Hospital Emergency Care Council (PHECC) - PhD funding (SK). PHECC had no role in the study design, analysis or interpretation of data, or the decision to submit the study for publication.

\section{Author details}

'Graduate Entry Medical School and Centre for Interventions in Infection, Inflammation \& Immunity (4i), University of Limerick, Castletroy, Limerick, Ireland. ${ }^{2}$ Health Services Executive, National Ambulance Service College, Dublin, Ireland.

Received: 14 October 2014 Accepted: 24 November 2015

Published online: 02 December 2015

\section{References}

1. Grossman J. Continuing competence in the health professions. Am J Occup Ther. 1998;52:709-15.

2. The Pre-Hospital Emergency Care Council Strategic Plan 2011-2014. [https://www.phecitie/Images/PHECC/Publications\%20and\%20Media/ Strategic\%20Plans/Strategic\%20Plan\%202011-2014.pdf]

3. Sutherland K, Leatherman S. Professional regulation: does certification improve medical standards? BMJ. 2006;333:439-41.

4. Bury $G$, Janes $D$, Bourke $M, O^{\prime}$ Donnell $C$. The advanced paramedic internship: an important clinical learning opportunity. Resuscitation. 2007;73:425-9.

5. Figgis K, Slevin O, Cunningham JB. Investigation of paramedics' compliance with clinical practice guidelines for the management of chest pain. Emerg Med J. 2010;27:151-5.

6. Knox S, Cullen W, Collins N, Dunne C. First evaluation of CPD advanced paramedic teaching methods in Ireland. J Paramed Pract. 2013;5:29-35.

7. Norum J, Elsbak T. The ambulance services in northern Norway 2004-2008: improved competence, more tasks, better logistics and increased costs. Int J Emerg Med. 2010:3:69-74.

8. Studnek JR, Fernandez AR, Margolis GS. Assessing continued cognitive competence among rural emergency medical technicians. Prehosp Emerg Care. 2009;13:357-63.

9. Studnek JR, Fernandez AR, Shimberg B, Garifo M, Correll M. The association between emergency medical services field performance assessed by highfidelity simulation and the cognitive knowledge of practicing paramedics. Acad Emerg Med. 2011;18:1177-85.

10. Morrison AA. Resisting compulsory continuing professional education. Aust J Adult Community Educ. 1992;32:146-50.

11. Norman GR, Shannon SI, Marrin ML. The need for needs assessment in continuing medical education. BMJ. 2004;328:999-1001.

12. Henwood SM, Yielder J, Flinton D. Radiographers attitudes to mandatory CPD: a comparative study in the United Kingdom and New Zealand. Radiography. 2004;10:251-8.

13. Murphy C, Cross C, Mc Guire D. The motivation of nurses to participate in continuing professional education in Ireland. J Eur Ind Train. 2006;30:365-84. 
14. Timmins F. Cardiac nurses' views of continuing professional education. Eur J Cardiovasc Nurs. 2008;7:59-66.

15. Colthart I, Bagnall G, Evans A, Allbutt H, Haig A, Illing J, et al. The effectiveness of self-assessment on the identification of learner needs, learner activity, and impact on clinical practice: BEME Guide no. 10. Med Teach. 2008;30:124-45.

16. Ward M, Gruppen L, Regehr G. Measuring self-assessment: current state of the art. Adv Health Sci Educ Theory Pract. 2002;7:63-80.

17. International Resuscitation Conference and Skills Showcase. [http://www. resus.ie/timetable.html]. Accessed November 302015

18. Grant J. Learning needs assessment: assessing the need. BMJ. 2002;324:156-9.

19. Kühne-Eversmann L, Fischer MR. Improving knowledge and changing behavior towards guideline based decisions in diabetes care: a controlled intervention study of a team-based learning approach for continuous professional development of physicians. BMC Res Notes. 2013;6:1-7.

20. Davis D, Thomson O Brien MA, Freemantle N, Fredric M, Mazmanian P, Taylor-Vaisey A. Impact of formal continuing medical education. Do conferences, workshops, rounds and other traditional continuing education activities change physician behavior or health care outcomes? JAMA. 1999: 282:867-74.

21. Schostak J, Davis M, Hanson J, Brown T, Driscoll P, Starke I, et al. 'Effectiveness of Continuing Professional Development' project: a summary of findings. Med Teach. 2010;32:586-92.

22. Mansouri M, Lockyer J. A meta-analysis of continuing medical education effectiveness. J Contin Educ Health Prof. 2007;27:6-15.

23. Sturrock JBE, Lennie SC. Compulsory continuing professional development: a questionnaire-based survey of the UK dietetic profession. J Hum Nutr Diet. 2009;22:12-20

24. $\mathrm{O}^{\prime}$ Connor $\mathrm{AB}$. Reasons nurses participate in continuing education. Nurs Res. 1979;28:354-9.

25. Lee S, Read W, Poulos A. Continuing professional development: the perceptions of radiographers in New South Wales. Radiographer. 2010;57: 33-9.

26. Friedman A, Woodhead S. Approaches to CPD measurement. PARN: Bristol; 2008.

27. Haughey SL, Hughes CM, Adair CG, Bell HM. Introducing a mandatory continuing professional development system: an evaluation of pharmacists' attitudes and experiences in Northern Ireland. Int J Pharm Pract. 2007;15: 243-9.

28. Dawson DE, Brown WE, Harwell TS. Assessment of nationally recognised emergency medical technician certification training in the United States: the LEADS Project. Prehosp Emerg Care. 2003;7:114-9.

29. Mackler N, Wilkerson W, Cinti S. Will first-responders show up for work during a pandemic? Lessons from a smallpox vaccination survey of paramedics. Disaster Manag Response. 2007;5:45-8.

30. Boyle M, Koritsas S, Coles J, Stanley J. A pilot study of workplace violence towards paramedics. Emerg Med J. 2007;24:760-3.

31. Marco CA, Schears RM. Prehospital resuscitation practices: a survey of prehospital providers. J Emerg Med. 2003;24:101-6.

32. Australasian Competency Standards. [http://www.paramedics.org/content/ 2011/10/PA_Australasian-Competency-Standards-for-paramedics_July20111.pdf]. Accessed November 302015

33. National occupational competency profile for paramedics. [http:// paramedic.ca/site/nocp_area1?nav=02] Accessed November 302015

34. Continuing Professional Development and Your Registration. [http://www. hcpc-uk.org/assets/documents/10001314CPD_and_your_registration.pdf]. Accessed November 302015

\section{Submit your next manuscript to BioMed Central and we will help you at every step:}

- We accept pre-submission inquiries

- Our selector tool helps you to find the most relevant journal

- We provide round the clock customer support

- Convenient online submission

- Thorough peer review

- Inclusion in PubMed and all major indexing services

- Maximum visibility for your research

Submit your manuscript at www biomedcentral com/submit
C) BioMed Central 